\title{
Microscopy and Microanalysis Characterization Techniques used to Investigate Cultural Heritage Materials, Paintings and Pigments
}

\author{
R. Wuhrer ${ }^{1}$ and P. Dredge ${ }^{2}$
}

1. Advanced Materials Characterisation Facility (AMCF), University of Western Sydney, NSW, Australia

2. Art Gallery of New South Wales, Art Gallery Rd, Sydney, NSW, 2000, Australia

Art works and other cultural items that are collected in museums and art galleries are inherited from past generations, maintained in the present and bestowed for the benefit of future generations. These art works and cultural heritage materials such as buildings, monuments, books, works of art, and statues require to be preserved for them to exist for future generations.

Conservation involves the conservation and preservation of museum objects and historical monuments utilizing compositional and structural information obtained from modern analytical techniques. The conservation of oil paintings requires an understanding of the individual structure of each work of art. This often involves the need for 1) correct identification of the pigments used by the artist, 2) a detailed knowledge of the chemical interactions between these pigments and 3) an understanding of the artist's method of mixing colours and laying paint on the canvas [1-3].

Microscopy and microanalysis, through SEM/EDS analysis and X-ray mapping (XRM), are excellent tools for characterizing the distribution of elements and phases in art works and other cultural masterpieces that are collected.

The XRM analytical technique provides an image related to the distribution and relative abundance of elements within a given specimen and thus makes XRM particularly useful for i) identifying the location of individual elements, ii) mapping the spatial distribution of specific elements and iii) determining the reaction product (phases) within a sample [4-6]. SEM, X-ray microanalysis and XRM have been used for determination of the above points. With this information, conservation treatments can be specifically developed for particular oil paintings. A number of different art works have been investigated.

Small paint chips were carefully excised from pre-existing damaged regions in each work of art and embedded in polyester resin, matching the hardness of an aged oil paint film. These samples were then carefully cross-sectioned with a microtome and examined by optical microscopy and later carbon coated for SEM/EDS and XRM analysis. Each specimen was analyzed using a JEOL 840 SEM equipped with a Moran Scientific X-ray analysis and mapping system. SEI and BSE imaging was used to locate individual paint pigments for x-ray analysis. Many of the pigments used in this era contained a signature element, which was utilized to map the distribution of each pigment within a given layer.

A number of different paintings have been investigated over the last ten years and some of these include: 
- Claude Monet “Port-Goulphar, Belle-Île”(1887), which gave an insight into the painting technique used by Claude Monet by examining the interface between successive paint layers in each specimen [1].

- John Russell's “Mon ami Polite” (1900), which revealed this work was originally painted before 1900 and then repainted on the same canvas.

- Phillips Fox's painting "Summer" (1912), which gave an insight into why powdering and disintegration was occurring within the yellow regions of the painting alongside dark discoloration at the interface of the yellow and the green.

Recent investigations of Sidney Nolan's paintings are characterizing commercial enamel paint he favored called Ripolin. A collection of paint left in his studio in 1953 has provided this study with a unique reference collection of Ripolin paint alongside a number of other paint types including Dulux. EDS and XRM of both the reference paints and samples from actual paintings by Nolan is providing information about the inorganic composition of these paints and clarifying Nolan's use of different brands of paint.

A paint sample taken from Colonial head gave a multilayered image under backscattered imaging. These layers contained both barium sulphate and zinc oxide pigments. Chemical phase mapping was able to demonstrate the two pigments were used in the layers in quite different proportions to each other. Shape and morphology of the pigment particles in each layer also suggested very different paints.

Two black paints were also identified on paintings by Nolan with a black glossy Ned Kelly figure; First-Class Marksman 1946 and The Camp 1947, with the trace element distribution being different between the two. The lower layer matched the inorganic trace element analysis of the Ripolin black paint, and the upper was better matched to the can of black Dulux from Nolan's studio. This supported the inference that the Kelly figure was originally painted in Ripolin, but repainted by the artist in Dulux.

This paper will present the results from a number of art work investigations and demonstrate the use of SEM and EDS analysis, XRM and XRM post processing techniques in obtaining a better understanding of the artists techniques and selection of paints.

\section{References}

1. P. Dredge, R. Wuhrer and M. R. Phillips, "Monet's painting under the microscope", Microscopy and Microanalysis, 9, 2, 139-143 (2003).

2. R. White, P. S. Thomas, M. R. Philips, R. Wuhrer and J. P. Guerbois, "TG-MS Charaterization of the Reaction Products of Cadmium Yellow and Malachite Artists Pigments", Journal of Thermal Analysis and Calorimetry, Vol. 88 (2007) 1, 181-184.

3. R. White, P. Thomas, M.R. Phillips, K. Moran, R. Wuhrer,"X-Ray Mapping and Scatter Diagram Analysis of the Discoloring Products Resulting from the Interaction of Artist's Pigments", (2010), Microscopy and Microanalysis, pp. 1-5. Article in Press.

4. K. Moran and R. Wuhrer, "Quantitative Bulk and Trace Element X-Ray Mapping Using Multiple Detectors", Mikrochimica Acta, Vol. 155, pp. 59-66 (2006).

5. K. Moran and R. Wuhrer, "X-ray Mapping and Interpretation of Scatter Diagrams", Mikrochimica Vol. 155, pp. 209-217 (2006).

6. R. White, M. R. Phillips, P. Thomas and R. Wuhrer, "In-Situ Investigation of Discolouration Processes Between Historic Oil Paint Pigments”, Mikrochimica Acta, April 28, 2006. 